\title{
26460 - COLLOIDS USE IN THE PERIOPERATIVE SETTING: A CANADIAN REVIEW
}

\section{Keyvan Karkouti MD, Davy Cheng, MD; Sylvain Belisle, MD; Mitch Giffin, Janet Martin, PharmD; Toronto General Hospital, Toronto, ONTARIO, Canada}

INTRODUCTION: Colloidal blood volume expanders such as albumin and synthetic hydroxyethyl starches (HES)are commonly used perioperatively in Canada to improve hemodynamics and reduce the need for blood transfusion. The efficacy and safety of colloids have been evaluated in randomized trials across a number of surgical settings(1,2). However, little is known about the utilization of colloids in the real world setting. The purpose of this benchmark study was to describe the perioperative use of colloids in 14 surgical categories in Canadian teaching hospitals.

METHODS: Four teaching institutions from 3 Canadian provinces (Quebec, Ontario, British Columbia) participated. Local ethics approval was given. At each institution, information was collected retrospectively by chart review on standardized forms for the first 25 available consecutively identified patients from 14 surgical categories: abdominal aortic aneurysm (AAA), on-pump coronary artery bypass grafting (CABG), off-pump CABG, bowel resection, liver resection, craniotomy, thoracolumbar fusion, hip replacement, knee replacement, thoracotomy, hysterectomy, prostatectomy, liver transplant, and kidney transplant. Means (SD) were calculated for volume of colloids administered and for allogeneic RBC units transfused intraoperatively and up to 24 hours postoperatively. ANOVAs were calculated, and $\mathrm{p}<0.05$ was considered significant. RESULTS: A total of 1,344 eligible patients undergoing surgery between 2003 and 2005 were analyzed. Throughout the study period, a total of $60.0 \%$ of patients received colloids. The types of colloids received were as follows: $57.0 \%$ of patients received pentastarch (264/0.45), 13.0\% received albumin, and 2.3\% received mannitol. Crystalloid use was reported in $96.2 \%$ of the population. In total, $31.0 \%$ received $\mathrm{RBC}$ transfusions, and $32.6 \%$ received any blood product transfusion. Mean volume of pentastarch administered differed by surgical type $(\mathrm{p}=0.006)$, and was greatest in on-pump CABG, and liver transplant. Mean volume of albumin differed by surgical type $(\mathrm{p}<0.0001)$, and was greatest in liver transplant. Significant differences in colloids utilization and transfusion rates were found across institutions (Table 1).

DISCUSSION: In Canadian teaching hospitals, colloids are commonly used during major surgical procedures with pentastarch rather than albumin being the preferred solution of choice. Colloids utilization and transfusion rates differ significantly by type of surgery and by institution. REFERENCES:

1. Anesthesiology 2003;99:42-47.

2. Arch Surg 2004;139:552-563. 
Table 1: Colloids Utilization Intraoperatively and POD 0 by Institution, mean (SD)

\begin{tabular}{|l|l|l|l|l|}
\hline Institution & $\begin{array}{l}\text { Pentastarch } \\
(\mathrm{mL})\end{array}$ & $\begin{array}{l}\text { Albumin 5\% } \\
(\mathrm{mL})\end{array}$ & $\begin{array}{l}\text { Albumin 25\% } \\
(\mathrm{mL})\end{array}$ & $\begin{array}{l}\text { RBC transfusion } \\
\text { (units) }\end{array}$ \\
\hline 1 & $429(105)$ & $27(8)$ & $16(5)$ & $0.76(0.54)$ \\
\hline 2 & $160(134)$ & $83(44)$ & $31(46)$ & $0.68(0.76)$ \\
\hline 3 & $459(219)$ & 0 & $1(130)$ & $0.23(0.13)$ \\
\hline 4 & $431(298)$ & $103(65)$ & $14(13)$ & $1.23(1.36)$ \\
\hline p-value & $<0.0001$ & $<0.001$ & $<0.0001$ & $<0.001$ \\
\hline
\end{tabular}

